\title{
Improved Retrieval of Sea Ice Thickness and Density from Laser Altimeter
}

\author{
Vera Djepa \\ Department of Applied Mathematics and Theoretical Physics (DAMTP), Cambridge University, Cambridge, UK \\ Email: vd256@cam.ac.uk
}

Received 16 October 2014; revised 27 November 2014; accepted 10 December 2014

Copyright (C) 2014 by author and Scientific Research Publishing Inc. This work is licensed under the Creative Commons Attribution International License (CC BY). http://creativecommons.org/licenses/by/4.0/

(c) (i) Open Access

\section{Abstract}

The sensitivity of weather and climate system to sea ice thickness (SIT) in the Arctic is recognised from various studies. Decrease of SIT will affect atmospheric circulation, temperature, precipitation and wind speed in the Arctic and remotely. Ice thermodynamics and dynamic properties depend strongly on ice and snow thickness. The heat transfer through ice critically depends on ice thickness. Long term accurate SIT records with corresponding uncertainties are required for improved seasonal weather forecast and estimate of the sea ice mass balance. Satellite radar and Laser Altimeter (LA) provide long term records of sea ice freeboard. Assuming isostatic equilibrium, SIT is retrieved from the freeboard, extracted from radar altimeter (RA) or LA, where the snow depth, density, ice and water density are input variables in the equation for hydrostatic equilibrium to derive SIT from LA or RA. Different input variables (snow depth, density, ice and water density) with unknown accuracy have been applied from various authors to retrieve SIT and Sea Ice Draft (SID) from RA or LA, leading to not comparative results. Sea ice density dependence on ice type, thermodynamic properties and freeboard is confirmed with different studies. Sensitivity analyses confirm the great impact of sea ice density, snow depth and density on accuracy of the retrieved SIT and the importance of inserting variable ice density (VID) in the equation for hydrostatic equilibrium for more accurate SIT retrieval, weather and climate forecast. The impact of sea ice density and snow depth and density on retrieved SIT from the freeboard derived from LA and RA have been analyzed in this study using the equation for hydrostatic equilibrium, statistical and sensitivity analyses. An algorithm is developed to convert the freeboard, derived from LA in SIT, inserting VID in the equation for hydrostatic equilibrium. The algorithm is validated with field, laboratory studies and collocated SIT retrieved from RA on board Envisat. The accuracy of the developed algorithm is analyzed, using statistical and uncertainty analyses. It is found that the uncertainty of the retrieved SIT from LA is decreased 7.6 times (from $r_{h i}=59 \mathrm{~cm}$ for fixed ice density) if variable ice density is inserted in the equation for hydrostatic equilibrium. The SIT, which has been retrieved from the freeboard derived from LA is validated with collocated SIT derived from RA2 on Envisat, using variable ice density. The bias of the mean SIT derived from LA and RA has been reduced from $-1.1 \mathrm{~m}$ to about one millimeter when VID is applied to retrieve SIT from LA and 
RA. The results and algorithms, discussed in this paper are essential contribution to SIT and SID retrieval, satellite remote sensing, cryosphere, meteorology and improved weather and climate forecast.

\title{
Keywords
}

\author{
Sea Ice Thickness, Radar Altimeter, Laser Altimeter, Sea Ice Density, Freeboard, Arctic
}

\section{Introduction}

Sea ice plays an important role in the global climate system via feedbacks and ice-atmosphere heat exchange [1] [2]. The sea ice decline contributes to approximately one third of the observed increase in the central and northern European summer precipitation during 1979-2009 [3]. The ECHAM5 global atmospheric model simulations of the atmospheric response to decreased wintertime sea ice extend in the Barents and Kara seas shows that a small decrease in the ice concentration (from $100 \%$ to $80 \%$ ) would result in an anomalous cyclonic circulation over the Arctic Ocean, whereas a larger decrease (from $80 \%$ to $40 \%$ ) could result in an anticyclonic model predicted circulation, associated with easterly winds over the surrounding continents, which may generate winter cooling of about $-1.5^{\circ} \mathrm{C}$ in large parts of Eurasia and North America [4]. Model simulations show that if the winter sea ice in the Barents and Kara Seas drops down to 1\%, the circulation over the Arctic Ocean would turn to cyclonic again, generating winter warming over Eurasia and the USA. The model simulation confirm the high sensitivity of weather and climate forecast to accuracy of the SIT and the importance of a long term records of SIT distribution with corresponding uncertainties. The ice loss is linked to the sea ice albedo feedback and radiative greenhouse gas forcing. The ice thickness is essentially part of the lower boundary condition for Weather Research and Forecasting Model (WRF). Mesoscale simulations with the WRF have generally used a simple representation for sea ice thickness and for snow depth on sea ice. For instance, the Noah land surface model ((LSM) for versions 3.4.1 and earlier of WRF) specify a sea ice thickness of $3 \mathrm{~m}$. Because the ice thermodynamics and dynamic depend strongly on ice thicknesses the accuracy of the model forecast depends also on accuracy of the SIT distribution.

Accurate SIT estimate is important for model validations and better understanding of the recent climate change. SIT distribution may help to answer the question: Is the ice thickness change part of a negative trend in the Arctic ice thickness, natural, inter-annual variability, model or algorithms parameterization.

Satellite laser altimeter (LA) (Ice, Cloud and land Elevation Satellite (ICESat)), Radar Altimetry (RA) (e.g. ERS1, 2, Envisat and CryoSat-2), airborne (Operational IceBridge (OIB)) and Upward Looking Sonar (ULS) on submarine, as well as the future (European Space Agency (ESA)/Sentinel and the National Aeronautics and Space Administration (NASA)/ICESat-2 missions with on board Advanced Topographic Laser Altimeter System (ATLAS) (expected to be launched in 2015)) provide long term estimate of SIT and freeboard in the last three decades. The freeboard on snow/ice-air interface is extracted from LA by comparing the satellite distance from the snow or ice surface to that of ice free areas [5]. Using the equation for hydrostatic equilibrium the freeboard measurements from LA is converted to sea ice thickness, which is ice density $\left(\rho_{i}\right)$, snow depth $\left(h_{s}\right)$, density $\left(\rho_{s}\right)$ and water density $\left(\rho_{w}\right)$ depended as the SIT, retrieved from RA [6]. The SIT, which is available from the National Snow and Ice Data Centre (NSIDC) is calculated from the freeboard, derived from ICESat, inserting constant densities for water, $\rho_{W}=1023.9 \mathrm{~kg} \cdot \mathrm{m}^{-3}$, ice, $\rho_{i}=915.1 \mathrm{~kg} \cdot \mathrm{m}^{-3}$ and snow, $\rho_{S}$ (NSIDC, 2010). Different constant ice density $\left(\rho_{i}=925 \mathrm{~kg} \cdot \mathrm{m}^{-3}\right)$ has been inserted in the equation for hydrostatic equilibrium to calculate SIT using the freeboard, which was derived from ICESat [10]. The SIT which is derived from the freeboard, retrieved from LA (Airborne Topographic Mapper (ATM) on board OIB) is calculated by inserting in the equation of hydrostatic equilibrium fixed sea ice $\left(\rho_{i}=914.3 \mathrm{~kg} / \mathrm{m}^{3}\right)$, water $\left(\rho_{w}=1023.9 \mathrm{~kg} / \mathrm{m}^{3}\right)$ and snow $\left(\rho_{s}=\right.$ $264 \mathrm{~kg} / \mathrm{m}^{3}$ during the expedition in 2009 and $\rho_{s}=320 \mathrm{~kg} / \mathrm{m}^{3}$ during the expedition in 2010) densities, as well as snow thickness derived from the snow radar on board OIB [5], which is different from the snow depth, which was used to retrieve SIT from ICESat [7]. The SIT has been retrieved from RA2/Envisat inserting in the equation for hydrostatic equilibrium fixed $\rho_{i}=900 \mathrm{~kg} / \mathrm{m}^{3}$ [8] [9], $h_{s}$ and $\rho_{s}$ from Warren Climatology (WC) [10]. The SIT derived from Cryosat-2, is calculated for $\rho_{i}=882 \mathrm{~kg} / \mathrm{m}^{3}$ over MYI and $\rho_{i}=916 \mathrm{~kg} / \mathrm{m}^{3}$ over FYI, $h_{s}=0.5 h_{s}$ 
(WC) over FYI and $h_{s}$ (WC) over MYI, requiring a-priory information for ice type [11]. Sensitivity analyses, observations and laboratory study confirm the sensitivity of the retrieved SIT to potential errors associated with input variables $\left(\rho_{i}, \rho_{w}, \rho_{s}, h_{s}\right.$ and the freeboard derived from LA and RA) when the equation for hydrostatic equilibrium is applied [6] [12]. Using different input variables, with unknown accuracy in the equation for hydrostatic equilibrium to convert the freeboard (which is derived from RA and LA) into SIT, is leading to not comparative results of SIT and high biases of the derived SIT from different instruments [12]. Theoretical [13], experimental [14], field [15] studies and sensitivity analyses [12] confirm the wide range of variability of sea ice density (from $720 \mathrm{~kg} / \mathrm{m}^{3}$ to about $940 \mathrm{~kg} / \mathrm{m}^{3}$ ) [16] and that the use of a constant ice density to retrieve SIT from the freeboard, derived from LA or RA will lead to not accurate estimate of SIT for the areas with different ice density due to $\rho_{i}$ dependence on ice freeboard, thermodynamic properties and thickness of sea ice. The sensitivity analyses confirms that use of inaccurate $\rho_{i}$ may lead to up to $2.7 \mathrm{~m}$ bias in the retrieved SIT for $h_{f i}=0.27 \mathrm{~m}$ in absence of snow depth [12]. The uncertainty analyses and validation studies confirm the increased accuracy of the derived SIT from RA if variable ice density (VID) is inserted in the equation of hydrostatic equilibrium to convert the freeboard into SIT [12]. Comparison of the collocated SIT derived from different instruments (RA/ERS-1/2, RA2/Envisat and ULS) show minimum biases when VID algorithm is applied and the same input parameters $\left(\rho_{w}, \rho_{s}\right.$, and $\left.h_{s}\right)$ are inserted in the equation for hydrostatic equilibrium to convert the freeboard into SIT [12].

The purpose of this study is to develop and validate algorithm with corresponding error analysis to retrieve sea ice density and convert the freeboard (derived from LA) in SIT for climate applications, providing minimum bias with collocated SIT from independent satellite observations from RA. The paper is organized as follows: 1) The hydrostatic equations to convert the freeboard derived from RA and LA into SIT and the impact of contributing factors are discussed in Section 2; 2) Sensitivity, uncertainty analysis and retrieval of VID to derive SIT from LA are provided in Section 3; 3) Validation of the derived SIT from LA, using variable ice density and collocated SIT from RA is given in Section 4; 4) the final conclusions are provided in the last Section 5.

\section{SIT Retrieval from the Freeboard Derived from Laser and Radar Altimeter}

The SIT has been derived from the freeboard, retrieved from LA on board ICESat [7] [17], OIB/ATM [5] [17], or from RA on board ERS1, 2, Envisat and Cryosat-2 [8] [11], using the equation for hydrostatic equilibrium. Conversion of the freeboard, derived from LA and RA into SIT is freeboard, $h_{s}, \rho_{s}, \rho_{i}, \rho_{w}$ dependent and the accuracy of the retrieved SIT depends on accuracy of the input variables.

The OIB mission has been developed to cover the gap between ICES at and ICESat2 for operational observations of ice thickness in the Arctic and Antarctic and data from OIB are available from the NSIDC [17]. The SIT is retrieved from the geo-located freeboard $\left(h_{f}\right)$ derived from the laser altimeter (ATM) on board OIB [17], applying the equation for hydrostatic equilibrium, which is snow depth, density, ice density and freeboard dependent, using constant ice density. The equation for hydrostatic equilibrium and the impact of input variables on retrieved SIT from the freeboard, derived from RA and LA are described in the next subsections.

\subsection{Conversion of the Freeboard Derived from Laser Altimeter into Sea Ice Thickness}

The SIT derived from laser altimeter (ATM) has been calculated by Equation for hydrostatic equilibrium, using different constant input variables for $h_{s}, \rho_{i}, \rho_{s}, \rho_{w}$ [5] [6]. Use of constant different snow densities $\left(\rho_{s}=264\right.$ $\mathrm{kg} / \mathrm{m}^{3}$ during expedition in 2009 and $\rho_{s}=320 \mathrm{~kg} / \mathrm{m}^{3}$ during expedition in 2010 [18], not accounting for snow grain and roughness may lead to inaccurate snow depth retrieval in locations with different snow density and not precise estimation of $h_{s}$ and SIT from LA/ATM. The retrieved freeboard $\left(h_{f}\right)$ from LA is converted into sea ice thickness, $h_{i}$, applying the equation for hydrostatic equilibrium:

$$
h_{i}=\rho_{w} h_{f} /\left(\rho_{w}-\rho_{i}\right)-\left(\rho_{w}-\rho_{s}\right) h_{s} /\left(\rho_{w}-\rho_{i}\right)
$$

where $h_{s}$ is the snow depth, $\rho_{i}, \rho_{s}, \rho_{w}$ are the ice, snow and water densities [6]. Considering that the laser altimeter measures the freeboard on air snow interface and accounting for Equation (1) the following relationship of the sea ice draft $d_{l a}$ and surface elevation $h_{f}$, measured from laser altimeter is obtained:

$$
d_{l a}=\left(h_{s}\left(\rho_{s}-\rho_{i}\right)+h_{f} \rho_{i}\right) /\left(\rho_{w}-\rho_{i}\right)
$$

where $h_{f}$ is the ice + snow (if present) surface elevation, measured by LA. 
The ratio $R$ of the sea ice draft and elevation is computed by:

$$
R=d_{l a} / h_{f}=\left(h_{s}\left(\rho_{s}-\rho_{i}\right)\right) / h_{f}\left(\rho_{w}-\rho_{i}\right)+\rho_{i} /\left(\rho_{w}-\rho_{i}\right)
$$

One can see that $h_{i}, d_{\text {la }}$ and $R$ depend on the same variables $h_{s} h_{f}, \rho_{s}, \rho_{i}, \rho_{w}$ and in absence of snow $R$ depends only on ice density (ice type). The ration $R$ will be constant for the same ice type and absence of snow even if the elevation changes. Use of a constant ice density will lead to constant $R$ for regions with $h_{s}=0 \mathrm{~m}$ and different ice types, which may lead to misleading assumption for the same ice type.

The SIT [17], which is derived from the freeboard retrieved from LA/ATM on board OIB (with uncertainty, $\sigma_{h f i}<0.03 \mathrm{~m}$ ), applying the equation for hydrostatic equilibrium (Equation (1)) and constant ice density $\left(\rho_{i}=\right.$ $915.1 \mathrm{~kg} \cdot \mathrm{m}^{-3}$ have been compared (for validation) with collocated SIT, which is retrieved from the freeboard, derived from RA2 on board Envisat (with the same uncertainties), using the Equation for hydrostatic equilibrium. In the next section is discussed the conversion of the freeboard, derived from RA into SIT.

\subsection{Conversion of the Freeboard, Derived from Radar Altimeter into Sea Ice Thickness}

Assuming hydrostatic equilibrium and that the radar returns are from snow-ice interface, the SIT, $h_{i}$, derived from RA is calculated as a function of snow depth $\left(h_{s}\right)$, density of water, $\rho_{w}$, ice, $\rho_{i}$, and snow, $\rho_{s}$ by [6]:

$$
h_{i}=\left(h_{s} \rho_{s}+h_{f i} \rho_{w}\right) /\left(\rho_{w}-\rho_{i}\right)
$$

The radar altimeter measures the freeboard on ice snow interface $\left(h_{f i}\right)$ in presence of dry snow and cold conditions, The sea ice draft (SID) retrieved from RA, as a function of sea ice freeboard $h_{f i}$, is calculated from the difference of SIT and the sea ice freeboard by:

$$
d_{r a}=h_{i}-h_{f i}=\left(h_{s} \rho_{s}+h_{f i} \rho_{w}\right) /\left(\rho_{w}-\rho_{i}\right)
$$

where $h_{i}$ is calculated by Equation (4), assuming that the radar return is on snow-ice interface. One can see that SIT, derived from RA depends on the same input variables and their uncertainties as the SIT derived from laser altimeter (snow depth and density, ice, water density and freeboard). Collocated sea ice draft, derived from RA (on board ERS and Envisat), with the sea ice draft, derived from ULS, in the Arctic has been used to validate the algorithm for SIT retrieval, using the freeboard derived from RA to calculate SIT applying 6 algorithms and the algorithm with variable ice density was selected, providing minimum bias of the SID derived from RA and ULS [12].

The collocated SIT, retrieved from LA and RA using constant $\rho_{i}$ and variable $\rho_{i}$ will be validated in Section 4. The impact of the input variables $\left(h_{s}, \rho_{s}, \rho_{i}, \rho_{w}\right.$ and $\left.h_{f i}\right)$ on the retrieved SIT, applying the equation for hydrostatic equilibrium will be discussed in the next sub-sections.

\subsection{Impact of Sea Ice and Water Density on Retrieved SIT from LA}

The sea water density, $\rho_{w}$, depends on salinity, $S$, temperature, $T$, and pressure and ranges from about 1022 $\mathrm{kg} / \mathrm{m}^{3}$ at the sea surface to $1050 \mathrm{~kg} / \mathrm{m}^{3}$ at the bottom of the ocean. The density of sea water across the Beaufort Shelf and slope off Alaska varies between $1023.2 \mathrm{~kg} / \mathrm{m}^{3}$ in October to $1024.2 \mathrm{~kg} / \mathrm{m}^{3}$ in April and a mean value of $\rho_{w}=1024 \mathrm{~kg} / \mathrm{m}^{3}$ has been used for SIT retrieval from ICES at [7]. Water density $\rho_{w}=1025 \pm 0.5 \mathrm{~kg} / \mathrm{m}^{3}$ has been used to calculate mean MYI sea ice density $\left(882 \mathrm{~kg} / \mathrm{m}^{3}\right)$ [16].

The density of sea ice depends on density of pure ice, the fractional volume of air pockets and the sea ice freeboard [16]. The density of pure ice at $0^{\circ} \mathrm{C}$ is $916.4 \mathrm{~kg} \cdot \mathrm{m}^{-3}$ and is increasing to $919.3 \mathrm{~kg} / \mathrm{m}^{3}$ at $-30^{\circ} \mathrm{C}$ [19]. The density of sea ice can be greater than these values because of the effect of brine inclusions in the ice, or less because of the effect of air bubbles, temperature and ice type. Sea ice densities below the waterline have typical values between 920 and $940 \mathrm{~kg} \cdot \mathrm{m}^{-3}[16]$.

Sea ice density has been calculated from different authors as a function of $h_{f}, h_{s}$ and $\rho_{s}$, using the equation for isostatic equilibrium, or field observations [15] [16]. The MYI $\rho_{i}$ can vary between 720 and $900 \mathrm{~kg} \cdot \mathrm{m}^{-3}$ and the ice density depends on temperature, free-board, snow depth, or melting [16]. The typical FYI $\rho_{i}$ is in the range $910-920 \mathrm{~kg} \cdot \mathrm{m}^{-3}$ [19]. Mean MY ice density $882 \pm 23 \mathrm{~kg} / \mathrm{m}^{3}$ is calculated by [16], which is less than $\rho_{i}=914.3$ $\mathrm{kg} \cdot \mathrm{m}^{-3}$, used by [5] to derive SIT from ATM/OIB and the ice density $\left(925 \mathrm{~kg} / \mathrm{m}^{3}\right)$ used by [7] to derive SIT from ICES at. Using fixed, different ice densities will lead to not comparative results of SIT, derived from ATM/OIB, ICES at, or RA for the same conditions (freeboard, snow depth, ice type and temperature). Surface observations 
[15], experimental studies [14] and sensitivity analyses confirm dependence of $\rho_{i}$ on ice type, thermodynamic properties and $h_{f i}$. A linear relationship has been obtained between $\rho_{i}$ and "effective" ice free-board, $h_{\text {fie }}(\mathrm{m})$, which depends on sea ice freeboard, $h_{f i}$, snow depth, $h_{s}$, density, $\rho_{s}$ and the mean MY ice density [15]. By comparison with in-situ (drilling) observations, it was concluded that a VID model provides more accurate results for freeboard to SID conversion using the equation for hydrostatic equilibrium, compared with fixed sea ice density, used to convert the freeboard into sea ice draft. The following regression of sea ice density, $\rho_{\mathrm{iKO}}$, on SIT has been derived based on laboratory study, confirming the $\rho_{i}$ dependence on $h_{i}$ [14]:

$$
\rho_{\text {iКо }}=0.9363-0.0018 h_{i}^{0.5}
$$

Observations [15] [16] and laboratory study [14] confirm the wide range of sea ice density variations and $\rho_{i}$ dependence on $h_{f i}, h_{i}, h_{s}$ and $\rho_{s}$. Variable ice density algorithm (described in Section 2.5), inserted in the equation for hydrostatic equilibrium (Equation (1)) has been validated with the field [15], laboratory study [14] and collocated SIT, derived from RA (Section 4). The impact of snow depth on retrieved SIT from LA is discussed in the next subsection.

\subsection{Impact of Snow Depth on Retrieved Sea Ice Thickness from Laser Altimeter}

Snow depth is an input variable to retrieve SIT from LA, using the hydrostatic equation (Equation (1)). Snow is a dielectric structure consisting of air, ice particles and liquid water. The dielectric constant of snow is a function of frequency, temperature, volumetric water content, snow density, shape of ice particles and water inclusion. Wet snow is a mixture of ice crystals, liquid water and air, and the dielectric constant of snow over sea ice depends on salinity. The density of wet snow can be approximated as a function of density of dry snow and volumetric water content (W). The snow, that is older than one year (over MYI) is a mixture of ice and water particles with different grain size and particle volume content and may becomes glacier ice, leading to ice scattering on effective freeboard within the snow layer. Presence of ice particles, ice lenses or frozen snow pack lead also to ice density contribution within the snow pack. Observations and model simulations confirm internal ice layers and presence of an effective ice freeboard within the snow pack, depending on $h_{\mathrm{fi}}, h_{s}$ and $\rho_{s}$. Models demonstrate that the snow density changes due to melt frees metamorphism and when the water freezes the snow density increases [13]. Snow crusts that occur after refreezing of melted snow can achieve densities of $700-800 \mathrm{~kg} \cdot \mathrm{m}^{-3}$. The older than one year snow is a mixture of ice and water particles with different grain size and particle volume content and may become glacier ice at a density of about $830 \mathrm{~kg} \cdot \mathrm{m}^{-3}$, which is leading to radar signal scattering within the snow layer. Thus, the radar scattering surface depends on $h_{s}, \rho_{s}$ and $h_{f i}$ and is equal to $h_{f i}$ if there is no snow on the ice surface or in presence of dry snow. The ice freeboard for laser altimeter could be within the snow layer in presence of frozen snow, or snow crusts that occur after refreezing of melted snow. Snow depth derived from WC, AMSRE, OIB snow radar, or models have been inserted in Equation (1) from different authors to retrieve SIT from LA, which lead to different results [5] [6]. The snow depth and density from WC are validated over about 40 years in the Arctic and are available with corresponding uncertainties as a function of latitude, longitude and mean monthly snow depth [10]. WC has been used successfully until now for low resolution (100 km spatial and 1 month temporal resolution) SIT retrieval from RA, ICESat and CryoSat-2 with climate applications [7]-[9] [11]. Recent limited high resolution observations of snow depth from buoy, OIB/snow radar and microwave radiometer (AMSR-E) suggested decreased snow depth over First Year Ice (FYI) with not proofed accuracy [18] [20] [21]. AMSR-E snow depth retrieval algorithm, ECMWF re-analyses and surface observations [21] confirm underestimation of the observed snow depth from AMSR-E satellite observations. The snow depth, retrievals from the OIB snow radar, depends on accuracy of estimated air-snow and snow-ice interfaces [5] and the distance between the two interfaces, which is a function of snow and air dielectric constants and snow density. Very low constant snow density $\left(264 \mathrm{~kg} / \mathrm{m}^{3}\right)$ has been used to retrieve snow depth in April 2009 [18]. The mean snow density from WC for this month is $\rho_{s}=320 \mathrm{~kg} / \mathrm{m}^{3}$ [10] and for FYI the $\rho_{s}=324$ $\mathrm{kg} / \mathrm{m}^{3}$ [16]. Because snow density vary from $260 \mathrm{~kg} / \mathrm{m}^{3}$ to $430 \mathrm{~kg} / \mathrm{m}^{3}$, different snow depth will be retrieved for snow density higher than $260 \mathrm{~kg} / \mathrm{m}^{3}$. Due to relatively low difference between the dielectric constants for air and snow, as well as the impact of surface roughness, the air-snow interface is difficult to detect with OIB/radar and a threshold is set to identify the top of the snow layer within the radar return, which depends on ice-snow interface and measured standard deviation, leading to snow depth dependence on sea ice freeboard. The sea ice freeboard is on sea/ice interface only for dry and cold conditions (if snow melting did not take place in the past) and can be within snow layer in presence of ice particles, ice lenses or frozen snow pack. The accuracy of the re- 
trieved snow depth from the OIB snow radar depends on the accuracy of estimated snow-air interface, ice-snow interface and snow density. Thus, using constant snow density, not accounting for snow grain and roughness, and considering the strong dependence of the algorithm on snow-ice and snow-air freeboards, may lead to inaccurate snow depth retrieval from OIB/radar in locations with different snow density or not precise estimation of $h_{f i}$ or $h_{f s}$. According to [5] there were not validation data for snow depth, retrieved from OIB/radar in 2010 and the algorithm was changed, which makes questionable the accuracy of the retrieved snow depth from OIB/snow radar. Collocated $h_{s}$ (from WC and OIB snow radar), freeboard $\left(h_{f}\right.$ ) (derived from ATM/OIB with uncertainty $\sigma_{h f}$ $<0.03 \mathrm{~m}$ ), averaged in $100 \mathrm{~km}$ spatial resolution and centered in the $h_{f i}$ averaged area (derived from RA with radius $100 \mathrm{~km}$ and uncertainty $\sigma_{h f i}<0.03 \mathrm{~m}$ ) have been used to calibrate the snow depth retrieval from the OIB snow radar and examine the $h_{s}$ impact on accuracy of the retrieved SIT. The statistic is provided in Table 1 and the area of observations, function of latitude (la) and longitude (lo) is shown on Figure 1(a).

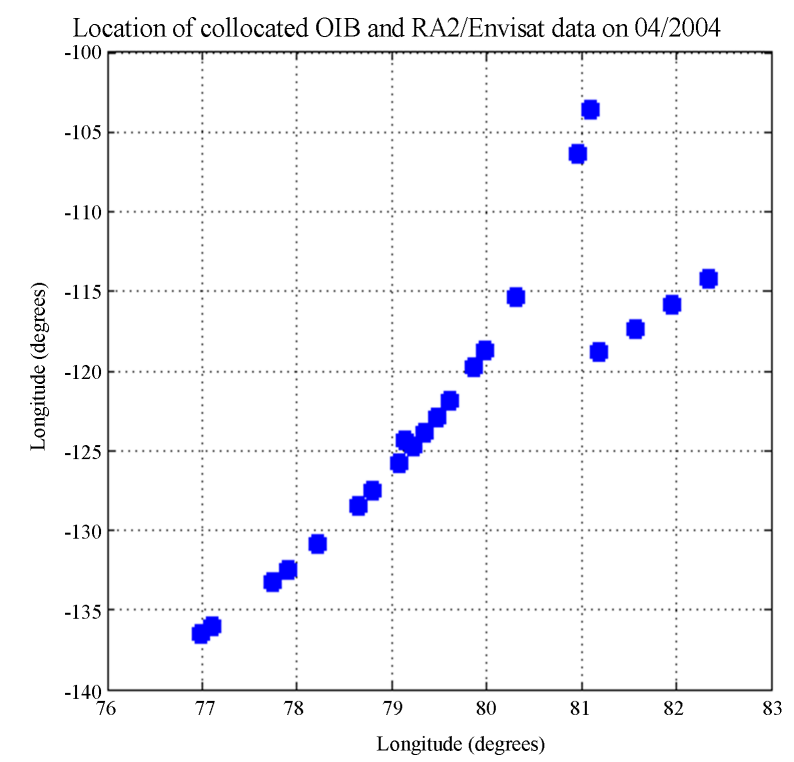

(a)

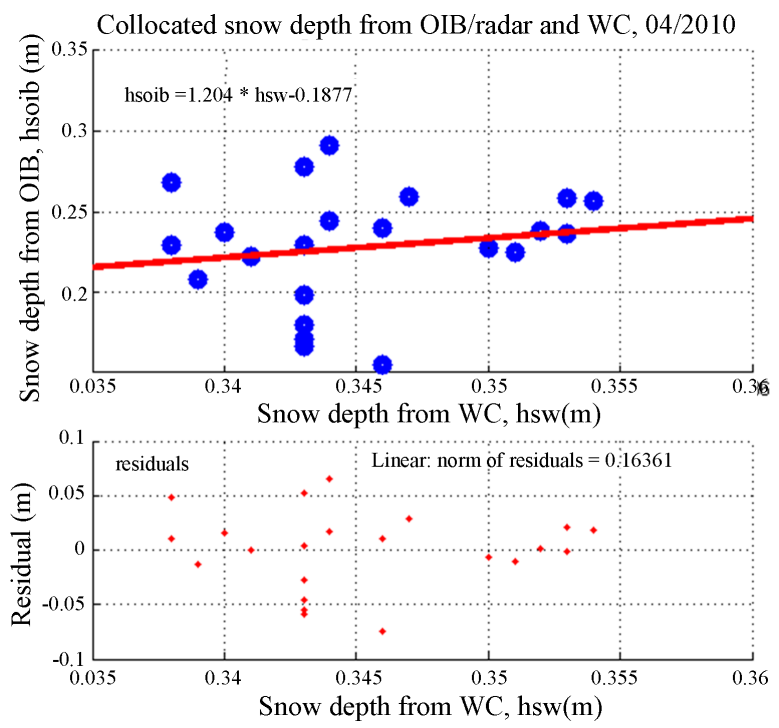

(b)

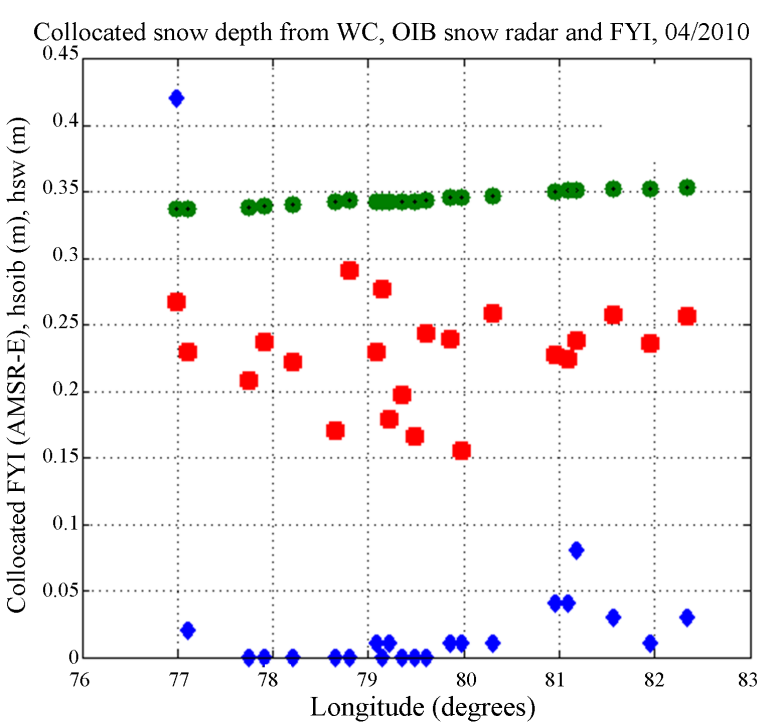

(c)

Figure 1. (a) Location of collocated data from OIB, on 04/2010 (in $100 \mathrm{~km}$ averaged area), centered in the averaged area (with $100 \mathrm{~km}$ radius) of the freeboard, retrieved from RA2/Envisat; (b) Collocated snow depth from OIB/radar and WC; (c) Collocated $h_{s}$ (WC) m, $h_{s}$ (OIB) $\mathrm{m}$ (red) and FYI ( $\left.100 \%\right)$ from AMSR-E (blue). 
Table 1. Statistic of collocated snow depth, freeboard and FYI, derived from OIB and RA2/Envisat.

\begin{tabular}{cccccccccc}
\hline Variable & $h_{f}(\mathrm{~m})$ OIB & $h_{f i}(\mathrm{~m}) \mathrm{RA}$ & $h_{f i w}(\mathrm{~m})$ OIB & $h_{f \mathrm{~b}}(\mathrm{~m})$ OIB & $h_{\text {sw }}(\mathrm{m})$ WC & $h_{\text {soib }}(\mathrm{m})$ OIB & FYI $(\%)$ & $\rho_{s}(\mathrm{WC}) \mathrm{kg} / \mathrm{m}^{3}$ & $\sigma_{h f}(\mathrm{~m})$ \\
\hline Mean & 0.542 & 0.1904 & 0.1964 & 0.314 & 0.345 & 0.228 & 3.27 & 303.9 & 0.0175 \\
Std & 0.0843 & 0.0626 & 0.0825 & 0.0918 & 0.005 & 0.0362 & 8.87 & 3.1 & 0.0057 \\
\hline
\end{tabular}

One can see that the sea ice freeboard $\left(h_{f i b}\right)$, estimated as a difference of the freeboard, $h_{f}$, derived from ATM/OIB and the snow depth, retrieved from OIB snow radar $h_{\text {soib }}$ is with $0.224 \mathrm{~m}$ higher than the ice freeboard, $h_{f i}$, derived from RA2. The bias of $h_{f i w}\left(h_{\text {fiw }}=h_{f}-h_{s w}(\mathrm{WC})\right.$, where $h_{s w}$ is the collocated snow depth from WC) and $h_{f i}$ is only $6 \mathrm{~mm}$, when, snow depth from WC is applied. The statistic (Table 1) and the regression of the snow depth (Figure 1(b)) derived from OIB radar and the $h_{s w}(\mathrm{WC})$ confirm that OIB radar underestimate the snow depth with $12 \mathrm{~cm}$ in comparison with $h_{s w}(\mathrm{WC})$ :

$$
h_{\text {soib }}=1.204 h_{\text {sw }}-0.1877(\mathrm{~m})
$$

The underestimated snow depth, derived from OIB/radar cannot be explained with presence of FYI because it is only $3.2 \%$ presence of FYI in the area (Table 1), estimated from the collocated AMSR-E data. One can see that it is not any correlation $(r=0.273)$ between the $\mathrm{h}_{\text {soib }}$ and presence of FYI (Figure 1(c)), which confirms that the lower $h_{\text {soib }}$ values measured by OIB/snow radar are due to algorithm restrictions, but do not depend on presence of FYI. The mean snow density from WC for the observed area is $\rho_{s}=303.9 \mathrm{~kg} / \mathrm{m}^{3}$ (Table 1 ) and using a different constant snow density $\left(\rho_{i}=320 \mathrm{~kg} / \mathrm{m}^{3}\right)$ [5] to derive snow depth from OIB/snow radar is introducing error in the retrieved snow depth, which will impact the accuracy of the SIT derived from ATM/OIB. Use of a very low snow depth, constant snow and ice density $\left(\rho_{i}=914.3 \mathrm{~kg} / \mathrm{m}^{3}\right)$ [5], corresponding to FYI, in presence of MYI, will lead to over estimated SIT, derived from ATM/OIB, confirmed with statistic (Section 4). Statistics (Table 1) confirm the applicability of WC $\left(h_{s w}\right)$ to retrieve low resolution SIT from ATM/OIB (with climate applications), providing only $6 \mathrm{~mm}$ bias with the ice freeboard derived from RA, compared with $22.4 \mathrm{~cm}$ bias when snow depth from OIB/radar has been used. Equation (7) can be applied to improve and calibrate the algorithm for low resolution snow depth retrieval from OIB/snow radar. Retrieval of effective freeboard and the algorithm for VID, using $h_{s w}$ and $\rho_{s}$ from WC is discussed in the next subsection.

\subsection{Algorithm for Variable Ice Density}

Using the equation for hydrostatic equilibrium (Equation (1)), $\rho_{i}$ has been calculated for a wide range of input variables $h_{\mathrm{fi}}$ (from $0.09 \mathrm{~m}$ to $0.45 \mathrm{~m}$ ), $\rho_{s}$ (from $260 \mathrm{~kg} / \mathrm{m}^{3}$ to $360 \mathrm{~kg} / \mathrm{m}^{3}$ ), $h_{s}$ (from $0.01 \mathrm{~m}$ to $0.38 \mathrm{~m}$ ) and $\rho_{w}=$ $1024 \mathrm{~kg} / \mathrm{m}^{3}$. The simulated $\rho_{i}$ have been compared with the $\rho_{i}$ derived from field observations [15] and laboratory study [14] and a linear dependence of a VID $\left(\rho_{i V I D}\right)$ and an effective freeboard $\left(h_{f i e}\right)$ has been retrieved. Regression coefficients have been derived satisfying the best fit of simulated $\rho_{i \mathrm{VID}}$ with that derived from the field and laboratory study:

$$
\rho_{\mathrm{iVID}}=a h_{\text {fie }}+b
$$

where $\mathrm{a}=-95.05, \mathrm{~b}=930.4$, mean ice density for FYI $\left(\rho_{\text {iFYmean }}=910 \mathrm{~kg} / \mathrm{m}^{3}\right)$ and $h_{\text {fie }}<0.18 \mathrm{~m}$;

$\mathrm{a}=-214, \mathrm{~b}=948$, mean ice density for MYI $\left(\rho_{\text {iMYmean }}=882 \mathrm{~kg} / \mathrm{m}^{3}\right)$ and $0.18 \mathrm{~m}<h_{\text {fie }}<0.37 \mathrm{~m}$;

$\mathrm{a}=-36.54, \mathrm{~b}=903.7$, mean ice density for MYI $\left(\rho_{\text {iMYmean }}=882 \mathrm{~kg} / \mathrm{m}^{3}\right)$ and $h_{\text {fie }}>0.37 \mathrm{~m}$.

The mean ice density of MYI $\left(\rho_{i M Y \text { mean }}=882 \mathrm{~kg} / \mathrm{m}^{3}\right)$, retrieved by [16] and $\rho_{i F Y \text { mean }}\left(\rho_{i F Y \text { mean }}=910 \mathrm{~kg} / \mathrm{m}^{3}\right)$ for FYI, estimated based on laboratory study [14] have been inserted in Equation (9) to calculate the effective scattering surface $\left(h_{\text {fie }}\right)$, which is approximated as a function of $h_{f i}, h_{s}, \rho_{s}$ and the mean MY and FY ice density, $\rho_{\text {imean }}$ :

$$
h_{\text {fie }}=h_{f}-h_{s}+\left(h_{s} \rho_{s} / \rho_{\text {imean }}\right)=h_{\text {fiw }}+C
$$

where $h_{s}$ and $\rho_{s}$, calculated as a function of latitude and longitude from WC and collocated with the freeboard, derived from LA are inserted in Equation (9). The sea ice freeboard for cold and dry conditions, $h_{\text {fiw }}$, is calculated as a difference of the $h_{f}$, derived from LA/OIB and $h_{s}(\mathrm{WC})$ and the effective scattering surface, $h_{\text {fie }}$ is equal to $h_{\text {fiw }}$ if it is not snow on the ice surface. The effective scattering layer within the snow pack depends on $h_{s}, \rho_{s}$ and ice thermodynamic properties (determined by the $\rho_{\text {imean }}$ ), where $C_{\max }(\mathrm{FYI})=0.1286 \mathrm{~m}$ for $h_{\text {smax }}(\mathrm{WC})=0.36$ 
$\mathrm{m}, \rho_{\text {smax }}(\mathrm{WC})=325 \mathrm{~kg} \cdot \mathrm{m}^{3}$ and $\rho_{\text {imean }}=910 \mathrm{~kg} / \mathrm{m}^{3}$, and $C_{\text {max }}(\mathrm{MIY})=0.1327 \mathrm{~m}$ for $\rho_{\text {imean }}=882 \mathrm{~kg} / \mathrm{m}^{3}$. The uncertainty of the retrieved variable ice density $\left(\rho_{i \mathrm{VID}}\right)$ depends on uncertainties of the sea ice freeboard, $h_{f i}$. For example, the uncertainty of the VID is $\sigma_{\rho i M Y V I D}= \pm 3.45 \mathrm{~kg} / \mathrm{m}^{3}$ for MYI and $\sigma_{\rho i F Y V I D}= \pm 2.85 \mathrm{~kg} / \mathrm{m}^{3}$ for $F Y I$ and the sea ice freeboard uncertainty $\left(\sigma_{h f i} \pm 0.03 \mathrm{~m}\right)$, where $\sigma_{\rho i \mathrm{VID}}$ will decrease if the accuracy of $h_{f i}$ increases. The impact of the ice density and snow properties on accuracy of the retrieved SIT from LA and RA, using the equation for hydrostatic equilibrium, is estimated by sensitivity and uncertainty analyses.

\section{Sensitivity and Uncertainty Analyses of the Retrieved Sea Ice Thickness from Laser and Radar Altimeter}

Sensitivity analysis is applied to estimate sensitivity of the retrieved SIT from LA to input variables. Uncertainty analysis is applied to estimate the error of the retrieved SIT from LA, applying the equation for hydrostatic equilibrium.

\subsection{Sensitivity of the Retrieved Sea Ice Thickness from Radar and Laser Altimeter}

The sensitivity of SIT to input variables $\left(\rho_{i}, h_{s}\right.$ and $\left.h_{f i}\right)$ is analyzed (applying the equation for hydrostatic equilibrium) where SIT is calculated for $\rho_{i}=720-950 \mathrm{~kg} / \mathrm{m}^{3}, h_{f i}=0.09-0.45 \mathrm{~m}, h_{s}=0-140 \mathrm{~cm}, \rho_{s}$ from WC and $\rho_{w}$ $=1024 \mathrm{~kg} / \mathrm{m}^{3}$ (see Figure 2).

The sensitivity analyses (Figure 2) shows that the impact of ice density on retrieved SIT is essential and the snow depth impact increases when $h_{s}$ increases. The impact of change of snow depth (from 0 to $140 \mathrm{~cm}$ ) and ice density (from 720 to $950 \mathrm{~kg} / \mathrm{m}^{3}$ ) on standard deviations of the derived SIT, using the equation for hydrostatic equilibrium is shown in Table 2.

For snow depth $30 \mathrm{~cm}$, the standard deviation of retrieved SIT due to impact of ice density is up to $1.04 \mathrm{~m}$. The impact of ice density on uncertainties of the retrieved SIT is $0.78 \mathrm{~m}$ in presence of bare ice and increases with only $9 \mathrm{~cm}$ if the $h_{s}$ increases with $10 \mathrm{~cm}$, which confirms higher impact of ice density variations on uncertainties of the derived SIT, compared with the $h_{s}$ impact. The sensitivity analyses confirms that the ice density is the most important variable that impacts the accuracy of the SIT retrieved from LA and use of inaccurate $\rho_{i}$ may lead to up to $2.7 \mathrm{~m}$ bias in the retrieved SIT for $h_{f i}=0.27 \mathrm{~m}$ in absence of snow depth and ice density range (720 $\mathrm{kg} / \mathrm{m}^{3}<\rho_{i}<950 \mathrm{~kg} / \mathrm{m}^{3}$ ) (Figure 2). Only a variable freeboard-dependent ice density, which considers the ice type and snow depth along the RA track, will minimize the impact of uncertainties in the retrieved SIT from LA by inserting VID in Equation (1). The sensitivity analysis confirms that the ice density is the most important variable, which impacts the accuracy of the retrieved SIT from RA. The uncertainty of the derived SIT is up to $0.778 \mathrm{~m}$ due to $\rho_{i}$ impact (for $h_{f i}=0.01 \mathrm{~m}$ and $h_{s}=0 \mathrm{~m}$ ) and increase of the snow depth with $10 \mathrm{~cm}$ lead to increase of the standard deviation with only $9 \mathrm{~cm}$ when the equation for hydrostatic equilibrium is applied. Use of a wrong fixed ice density could introduce up to $3.6 \mathrm{~m}$ bias of the retrieved SIT for $h_{s}=30 \mathrm{~cm}$ (Figure 2). The uncertainties of the retrieved SIT from LA, inserting variable ice density, $h_{s}$ and $\rho_{s}$ from WC in the equation for hydrostatic equilibrium is discussed in the next section.

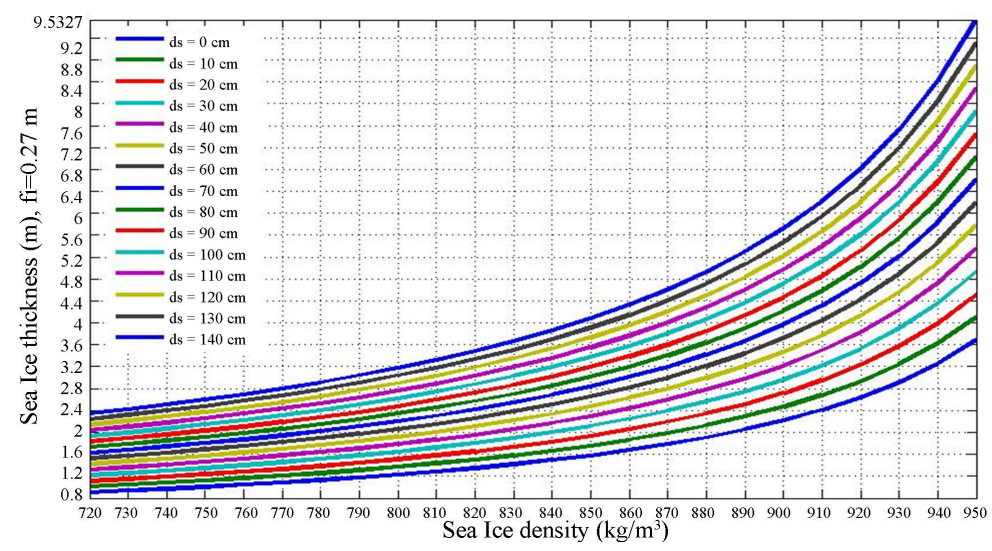

Figure 2. Sensitivity of SIT to sea ice density and snow depth $\left(d_{s}\right.$ denotes snow depth). 
Table 2. Standard deviation of SIT for snow depth from 0 to $140 \mathrm{~cm}$ and ice density from 720 to $950 \mathrm{~kg} / \mathrm{m}^{3}$.

\begin{tabular}{ccccccccc}
\hline$h_{s}(\mathrm{~cm})$ & 0 & 10 & 20 & 30 & 40 & 50 & 60 & 70 \\
\hline Std (m) & 0.7784 & 0.8664 & 0.9545 & 1.0425 & 1.1305 & 1.2186 & 1.307 & 1.395 \\
Var (m) & 0.6059 & 0.7507 & 0.9110 & 1.0868 & 1.2781 & 1.4849 & 1.707 & 1.945 \\
h (cm) & 80 & 90 & 100 & 110 & 120 & 130 & 140 & 2.011 \\
Std (m) & 1.4827 & 1.5707 & 1.6587 & 1.7468 & 1.8348 & 1.9228 & 4.044 \\
Var (m) & 2.1983 & 2.4671 & 2.7514 & 3.0512 & 3.3665 & 3.6973 & \\
\hline
\end{tabular}

\subsection{Uncertainty Analysis of the Retrieved SIT from LA}

Only the uncertainties, associated with conversion of freeboard to thickness (using the equation for hydrostatic equilibrium) will be analyzed. Assuming that the input variables in Equation (1) are uncorrelated, the uncertainty $\left(\varepsilon_{h i}\right)$ of the retrieved thickness, $h_{i}$, from the freeboard, measured from LA, will depend on propagated uncertainties of the input variables:

$$
\varepsilon_{h_{i}}=h_{i m} \sqrt{\varepsilon_{p}}
$$

where $h_{i m}$ is the mean ice thickness and the propagated uncertainty $\varepsilon_{p}$ is calculated from the standard deviations ( $\sigma_{h f}$ and $\sigma_{h s}, \sigma_{\rho s}, \sigma_{\rho w}, \sigma_{\rho i}$ ) of the freeboard, $h_{f}$, snow depth, $h_{s}$, snow, $\rho_{s}$, water, $\rho_{w}$, and ice, $\rho_{i}$, densities and corresponding mean values of all contributing factors (mean freeboard $\left(h_{f m}\right)$, water, ice and snow densities, $\rho_{w m}, \rho_{i m}$, $\rho_{\text {sm }}$ and snow depth, $\left.h_{s m}\right)$ :

$$
\begin{aligned}
\varepsilon_{p}= & \left(\sigma_{h f} / h_{f m}\right)^{2}+\left(\sigma_{\rho_{w}} / \rho_{w m}\right)^{2}+\left(\sigma_{\rho_{w}} / \rho_{w m}\right)^{2}+\left(\sigma_{\rho_{i}} / \rho_{i m}\right)^{2} \\
& +\left(\sigma_{\rho_{w}} / \rho_{w m}\right)^{2}+\left(\sigma_{\rho_{w}} / \rho_{w m}\right)^{2}+\left(\sigma_{\rho_{s}} / \rho_{s m}\right)^{2}+\left(\sigma_{\rho_{i}} / \rho_{i m}\right)^{2}+\left(\sigma_{h s} / h_{s m}\right)^{2} .
\end{aligned}
$$

The mean ice density $\left(h_{i m}\right)$, propagated $\varepsilon_{p}$ and total uncertainty, $\varepsilon_{h i}$, are calculated for the mean and standard deviations of the contributing factors of SIT derived from OIB (Table 1)) (inserting snow depth from OIB radar and constant snow $\left(\rho_{s m}=320 \mathrm{~kg} / \mathrm{m}^{3}\right)$ and ice density (including $h_{f m}=0.542 \mathrm{~m}, h_{s m}=0.2281 \mathrm{~m}, \rho_{s m}=320 \mathrm{~kg} / \mathrm{m}^{3}$, $\rho_{w m}=1024 \mathrm{~kg} / \mathrm{m}^{3}, \rho_{i}=314.3 \mathrm{~kg} / \mathrm{m}^{3}$ and corresponding standard deviations: $\sigma_{h f}=0.0175 \mathrm{~m}$ and $\sigma_{h s}=0.0362 \mathrm{~m}$, $\sigma_{\rho s}=19.2 \mathrm{~kg} / \mathrm{m}^{3}$ and $\left.\sigma_{\rho i}=25.15 \mathrm{~kg} / \mathrm{m}^{3}\right)$ and compared with $\varepsilon_{h i}$ when variable ice density is inserted in Equation (1) (using mean snow density and depth according to WC $\left(\rho_{s w}=303.9 \mathrm{~kg} / \mathrm{m}^{3}\right.$ with $\sigma_{\rho s w}=3.1 \mathrm{~kg} / \mathrm{m}^{3}, h_{s w}=0.345$ $\mathrm{m}, \sigma_{\text {hsw }}=0.005 \mathrm{~m}$ ), $\rho_{\text {imean }}=892.2 \mathrm{~kg} / \mathrm{m}^{3}$ and $\sigma_{\rho i}=3.05 \mathrm{~kg} / \mathrm{m}^{3}$ (see Table 4). The impact of fixed ice density (and snow depth from OIB/radar) and variable ice density (snow depth and density from WC) on accuracy of the retrieved SIT from LA is demonstrated with Table 3.

One can see from Table 3 that the uncertainty of the derived SIT applying variable ice density is decreased 7.6 times compared with the $\varepsilon \varepsilon_{h i}$ estimated for $h_{s}$ derived from OIB radar, fixed $\rho_{s}$ and $\rho_{i}$. The uncertainty $\varepsilon_{h i}$ will further decrease when a variable ice density is applied if the accuracy of the freeboard retrieval is increased. The propagated uncertainties of the retrieved SIT decrease (from 17.5\% to 3\%, Table 3) when VID ( $\rho_{i V I D}$ ) is inserted in the equation of hydrostatic equilibrium. The algorithm to retrieve SIT from LA using variable ice density has been validated using collocated SIT derived from RA2 on board Envisat.

\section{Validation of Sea Ice Thickness Derived from Laser Altimeter with Collocated Sea Ice Thickness Retrieved from Radar Altimeter}

A data base (Round Robin Data Package (RRDP)) of collocated SID and SIT from RA, OIB data, ULS and snow depth and density from WC have been developed as part of the European Space Agency (ESA) Climate Change Initiative (CCI) sea ice Essential Climate Variable (ECV) project (SICCI, 2013) [9]. The database includes the following collocated data sets: 1) snow depth and density from WC with the same spatial resolution, time and location as the averaged freeboard derived from RA data; 2) submarine ULS SID data averaged over $50 \mathrm{~km}$ and collocated with $h_{f i}$, derived from RA; 3 ) collocated snow depth, freeboard and SIT from NSIDC/OIB snow radar and laser scanner averaged over $100 \mathrm{~km}$; 4) presence of FYI (from AMSR-E); 5) collocated mean 
Table 3. Impact of fixed ice density (OIB) and VID on uncertainty of the derived SIT.

\begin{tabular}{ccccccc}
\hline Alg. & $\begin{array}{c}\text { OIB } \\
h_{\text {im }}\left(h_{s}(\mathrm{OIB})\right)\end{array}$ & $\sqrt{\varepsilon}_{\rho}\left(h_{s}(\mathrm{OIB})\right)$ & $\begin{array}{c}\text { OIB } \\
\varepsilon_{h i}\left(h_{s}(\mathrm{OIB})\right)\end{array}$ & $\begin{array}{c}\text { VID } \\
h_{i m}\left(h_{s}(\mathrm{WC})\right)\end{array}$ & $\sqrt{\varepsilon}_{\rho}\left(h_{s}(\mathrm{WC})\right)$ & $\begin{array}{c}\text { VID } \\
\varepsilon_{h i}\left(h_{s}(\mathrm{WC})\right)\end{array}$ \\
\hline $\mathrm{m}$ & 3.379 & 0.175 & 0.591 & 2.31 & 0.0369 & 0.0776 \\
\hline
\end{tabular}

Table 4. Statistics of the SIT derived from collocated freeboard, retrieved from laser and radar altimeter.

\begin{tabular}{|c|c|c|c|c|c|}
\hline Variable & SIT (LA, VID, $h_{s}(\mathrm{WC})$ ) & SIT (RA, VID, $\left.h_{s}(\mathrm{WC})\right)$ & SIT (RA, fixed $\left.\rho_{i}, h_{s}(\mathrm{WC})\right)$ & SIT (fixed $\rho_{i}, h_{s}(\mathrm{OIB})$ ) & $\rho_{i}\left(\mathrm{~kg} \cdot \mathrm{m}^{-3}\right)$ \\
\hline Mean (m) & 2.125 & 2.124 & 2.275 & 3.379 & 892.2 \\
\hline Std (m) & 0.445 & 0.358 & 0.455 & 0.750 & 3.053 \\
\hline B (m) & 0 & -0.001 & -1.1 & 0 & na \\
\hline
\end{tabular}

freeboard, derived from RA and RA2, averaged within an area of $100 \mathrm{~km}$ radius centered at each transect center.

The sea ice freeboard is derived from ERS1, 2/RA and Envisat/RA2 data using the methodology described in [9]. The VID algorithm has been validated with collocated SID from ULS and SID derived from RA (ERS1, 2 and Envsat) within 12 years in the Arctic and has been selected for SIT retrieval from the freeboard derived from radar altimeter based on statistics (minimum bias and RMSE) [12]. The freeboard derived (with uncertainties $\sigma_{h f}<0.03 \mathrm{~m}$ ) from NSIDC/OIB/LA/ATM, averaged in $100 \mathrm{~km}$ and centered in the averaged collocated freeboard, derived from RA2 (Envisat), $h_{s}$ and $\rho_{s}$ (from WC), OIB snow radar and presence of FYI from AMSR-E have been used for validation of the VID algorithm to retrieve SIT from LA. The collocated SIT (OIB/LA), calculated by Equation (1) (for fixed sea ice density of $914.3 \mathrm{~kg} / \mathrm{m}^{3}, \rho_{w}=1023.9 \mathrm{~kg} / \mathrm{m}^{3}$, snow $\rho_{s}=$ $320 \mathrm{~kg} / \mathrm{m}^{3}$ and snow depth from OIB radar [5]) with SIT, derived from RA2 (calculated by (Equation (4), (algorithm A1, applied to retrieve SIT from Envisat and ERS1, 2, using fixed $\rho_{i}=900 \mathrm{~kg} / \mathrm{m}^{3}, \rho_{w}=1030 \mathrm{~kg} / \mathrm{m}^{3}, \rho_{\mathrm{s}}$ and $h_{s}$ from WC) are compared and shown on Figure 3(a). The statistics are summarized in Table 4. Due to use of different input variables $\left(\rho_{w}, \rho_{s}, \rho_{i}\right.$ and $\left.h_{s}\right)$ to calculate SIT from laser and radar altimeter the mean bias is up to $-1.1 \mathrm{~m}$ (Table 4), which makes impossible use of SIT derived from LA/OIB for comparison and validation of low resolution SIT, retrieved from RA.

The collocated SIT, derived from laser and radar altimeter, applying VID algorithm, inserting (in Equation (1) and Equation (4)) and the same freeboard (used to calculate SIT on Figure 3(a)) are compared on Figure 3(b) and the statistics is given in Table 4. The bias is estimated as: $\mathrm{B}=$ mean $\left(h_{i}(\mathrm{OIB})-h_{i}(\mathrm{RA} 2)\right)$. One can see that the mean bias of SIT derived from RA2 and LA/OIB has been reduced (from $\mathrm{BB}=-1.1 \mathrm{~m}$ ) (for SIT calculated by RA2(A1) and LA(NSIDC/OIB), using different fixed ice densities and snow depth from OIB/radar) to B = $0.001 \mathrm{~m}$ when variable ice density (VID algorithm) has been applied to calculate SIT from LA and RA and the same snow depth. Figure 3 and Table 4 confirm the applicability of ATM/LA/OIB for validation of low resolution SIT, derived from RA, if the algorithm for variable ice density is inserted in Equation (1), using the same $\rho_{s}$ and $h_{s}$ to retrieve SIT from LA and RA. The improved bias of the SIT derived by LA/OIB and RA2 when VID algorithm is applied confirms the higher accuracy and reduced biases of derived SIT from RA and LA when a variable ice density is inserted in the equation for hydrostatic equilibrium to transform the measured freeboard from LA into SIT. The VID algorithm, integrated with $h_{s}$ and $\rho_{s}$ from WC, to retrieve SIT from ATM/OIB provides a new product of low resolution SIT from OIB/ATM, applicable for validation of SIT, derived from satellite RA for climate application. The VID algorithm provides also a sea ice density distribution, calculated from the freeboard, derived from ATM/OIB, which is important essential climate variable (ECV) for improved ice and climate model forecast. Statistic of the variable ice density (Table 4), calculated as a function of the measured snow freeboard from ATM/OIB, snow depth and density from WC, is given in Table 4. The following regression equations have been retrieved confirming the ice density dependence on $h_{i}$ and $h_{f}$ :

$$
\begin{gathered}
\rho_{i}=-5.3446 h_{i}+904.56, \text { with RMSE }=0.1574 \\
\rho_{i}=-36.17 h_{f}+911.8, \text { with RMSE }=0.1659
\end{gathered}
$$

where $h_{i}$ and $h_{f}$ are the SIT and freeboard derived from LA/ATM/OIB, using variable ice density.

Using the regression Equations (12)-(13), $\rho_{i}$ can be derived as a function of the measured freeboard from LA for energy balance calculation, weather and climate models validation. Ice density is important ECV and Equa- 


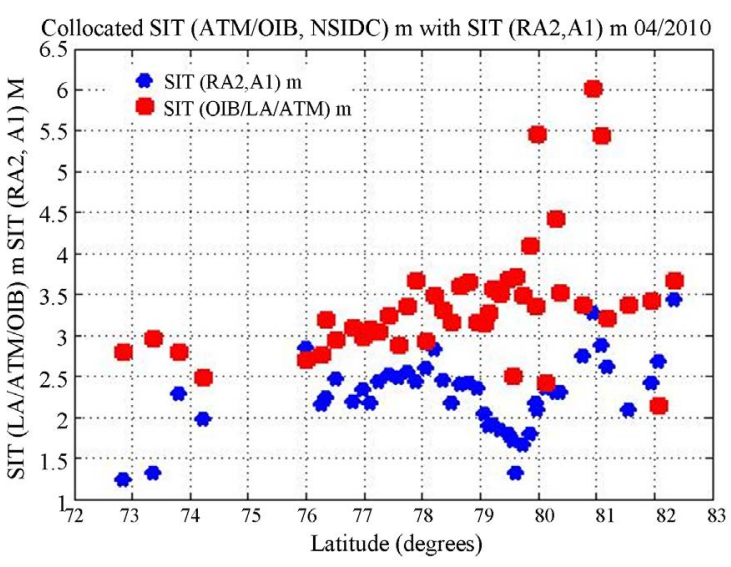

(a)

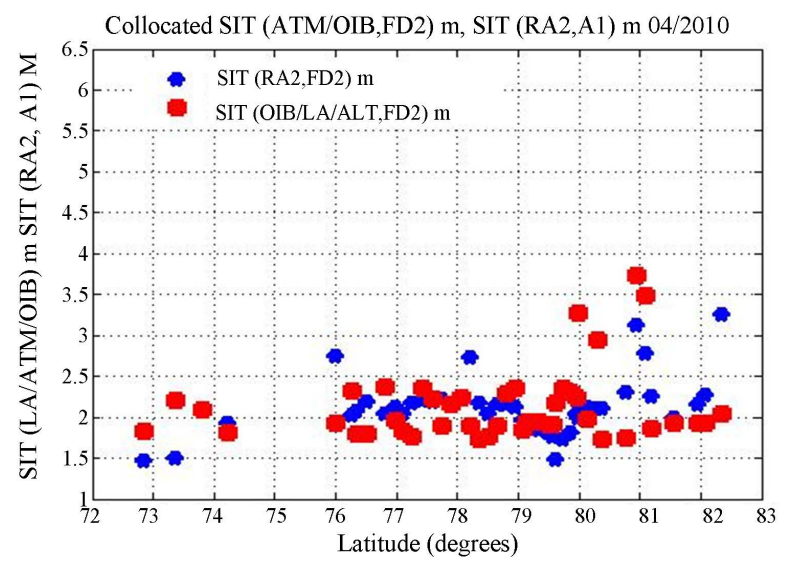

(b)

Figure 3. (a) SIT (OIB/LA, NSIDC) m (red), collocated with SIT (RA, A1) m (blue); (b) SIT (OIB/LA, VID) collocated with SIT (RA, VID).

tions (12)-(13) may have wide application for improved snow, ice, weather and climate forecast.

\section{Conclusions}

This paper has been focused on improved SIT and ice density retrieval from LA for climate applications. The main outcomes are:

1) Improved algorithm is developed and validated to convert the freeboard, derived from LA into SIT, using the equation for hydrostatic equilibrium and variable ice density. The algorithm has been applied to retrieve SIT from LA/OIB and validated with SIT derived from laboratory, field and satellite observations.

2) The impact of ice density and snow depth on accuracy of the retrieved SIT from LA is examined applying sensitivity analyses and equation for hydrostatic equilibrium. The sensitivity analyses confirms the high impact of ice density on accuracy of the derived SIT from LA ( $\sigma_{h i}=0.778 \mathrm{~m}$ due to $\rho_{i}$ impact, for $h_{f i}=0.01 \mathrm{~m}$ and $h_{s}=0 \mathrm{~m}$ ) and increase of the snow depth with $10 \mathrm{~cm}$ lead to only $9 \mathrm{~cm}$ increase of the $\sigma_{h i}$ when the equation for hydrostatic equilibrium is applied. Use of a wrong fixed ice density could introduce up to $3.6 \mathrm{~m}$ bias of the retrieved SIT for $h_{s}=30 \mathrm{~cm}$.

3) The impact of $h_{s}, h_{f}$ and $\rho_{s}$ on accuracy of the retrieved SIT from LA, is analyzed and compared, applying uncertainty analyses, inserting variable and fixed ice density in the equation for hydrostatic equilibrium. The uncertainty of the derived SIT applying variable ice density decreased 7.6 times compared with the $\varepsilon_{h i}$ estimated for $h_{s}$ derived from OIB radar, fixed $\rho_{s}$ and $\rho_{i}$.

4) The algorithm for variable ice density is validated by comparison of collocated SIT, derived from ATM/OIB, with SIT, retrieved from RA2 and the bias is reduced from $1.1 \mathrm{~m}$ to $1 \mathrm{~mm}$ when variable ice density is inserted in the equation for hydrostatic equilibrium, which confirms the accuracy of the developed VID algorithm and its applicability to create a long term time series of low resolution SIT, derived from LA and RA.

5) A new product of variable $\rho_{i}$, derived from LA/ATM/OIB is retrieved and regression equations are extracted confirming $\rho_{i}$ dependence on $h_{i}$ and $h_{f}$. Until now fixed ice density has been assumed for SIT retrieval and forecast. Extracting a variable ice density from the freeboard derived from LA/OIB is essential contribution for sea ice model validation, weather and climate forecast.

The developed algorithm to convert the freeboard, derived from LA in SIT, using variable ice density is essential contribution to ESA, NASA, NSIDC and climate programs, providing long term time series of SIT and ice density for climate and forecast models.

\section{Acknowledgements}

Thanks to Newton Trust, Cambridge University and ESA, SICCI project for support and providing collocated data for validation. 


\section{References}

[1] Cheng, B., Mäkynen, M., Similä, M., Rontu, L. and Vihma, T. (2013) Modelling Snow and Ice Thickness in the Coastal Kara Sea, Russian Arctic. Annals of Glaciology, 54, 105-113. http://dx.doi.org/10.3189/2013AoG62A180

[2] Stroeve, J., Holland, M.M., Meier, W., Scambos, T. and Serreze, M. (2007) Arctic Sea Ice Decline: Faster than Forecast. Geophysical Research Letters, 34, Article ID: L09501. http://dx.doi.org/10.1029/2007GL029703

[3] Screen, J.A. and Simmonds, I. (2013) Exploring Links between Arctic Amplification and Mid-Latitude Weather. Geophysical Research Letters, 40, 959-964. http://dx.doi.org/10.1002/grl.50174

[4] Petoukhov, V. and Semenov, V.A. (2010) A Link between Reduced Barents-Kara Sea Ice and Cold Winter Extremes over Northern Continents. Journal of Geophysical Research, 115, Article ID: D21111. http://dx.doi.org/10.1029/2009JD013568

[5] Kurtz, N.T., Farrell, S.L., Studinger, M., Galin, N., Harbeck, J., Lindsay, R., Onana, V., Panzer, B. and Sonntag, J.G. (2012) Sea Ice Thickness, Freeboard, and Snow Depth Products from Operation Ice Bridge Airborne Data. Cryosphere Discussions, 6, 4771-4827. http://dx.doi.org/10.5194/tcd-6-4771-2012

[6] Kwok, R. (2010) Satellite Remote Sensing of Sea Ice Thickness and Kinematics a Review. Journal of Glaciology, 56, 1129-1140. http://dx.doi.org/10.3189/002214311796406167

[7] Kwok, R., Cunningham, G.F., Wensnahan, M., Rigor, I. and Zwally, H.J. (2008) Thinning and Volume Loss of the Arctic Ocean Sea Ice Cover: 2003-2008. Journal of Geophysical Research, 114, Article ID: C07005. http://dx.doi.org/10.1029/2009JC005312

[8] Connor, L., Seymour, W., Laxon, B., Ridout, A.L., Krabill, W.B. and McAdoo, D.C. (2009) Comparison of Envisat Radar and Airborne Laser Altimeter Measurements over Arctic Sea Ice. Remote Sensing of Environment, 113, 563-570. http://dx.doi.org/10.1016/j.rse.2008.10.015

[9] (2013) Algorithm Theoretical Basis Document SICCI-ATBD. http://icdc.zmaw.de/fileadmin/user_upload/ESA_Sea-Ice-ECV/SICCI_ATBDv1_D2.6_Issue1.1.pdf

[10] Warren, S. and Rigor, I. (1999) Snow Depth on Arctic Sea Ice. Journal of Climate, 12, 1814-1829.

[11] Laxon, S., Giles, K.A., Ridout, A.L., Wingham, D.J., Willatt, R., Cullen, R., Kwok, R., Schweiger, A., Zhang, J., Haas, C., Hendricks, S., Krishfield, R., Kurtz, N., Farrell, S. and Davidson, M. (2013) CryoSat-2 Estimates of Arctic Sea Ice Thickness and Volume. Geophysical Research Letters, 40, 1-6. http://dx.doi.org/10.1002/grl.50193

[12] Djepa, V. (2014) Sensitivity Analyses of Sea Ice Thickness Retrieval from Radar Altimeter. Journal of Surveying and Mapping Engineering (JSME), 2, 44-55.

[13] Hallikainen, M. (1992) Review of the Microwave Dielectric and Extinction Properties of Sea Ice and Snow. Geosciences and Remote Sensing Symposium, IGARSS 92, 2, 961-965.

[14] Kovacs, A. (1996) Sea Ice. Estimating the Full Scale Tensile, Flexural and Compressive Strength. CRREL (Cold Regions Research and Engineering Laboratory) Report 96-11, Hanover, New Hampshire 03755-1290, USA.

[15] Ackley, S.F., Hibler III, W.D., Kugzruk, F., Kovacs, A. and Weeks, W.F. (1976) Thickness and Roughness Variations of Arctic Multiyear Sea Ice. CRREL (Cold Regions Research and Engineering Laboratory) Report 76-18, 24 p, Hanover, New Hampshire 03755-1290, USA.

[16] Alexandrov, V., Sandven, S., Wahlin, J. and Johannessen, O.M. (2010) The Relation between Sea Ice Thickness and Freeboard in the Arctic. The Cryosphere Discussion, 4, 373-380. http://dx.doi.org/10.5194/tc-4-373-2010

[17] NSIDC (National Snow and Ice Data Centre) (2014). http://nsidc.org/data/icebridge/

[18] Farrell, S.L., Kurtz, N.T., Connor, L., Elder, B., Leuschen, C., Markus, T., McAdoo, D.C., Panzer, B., Richter-Menge, J. and Sonntag, J. (2012) A First Assessment of Ice Bridge Snow and Ice Thickness Data over Arctic Sea Ice. IEEE Transactions on Geoscience and Remote Sensing, 50, 2098-2111. http://dx.doi.org/10.1109/TGRS.2011.2170843

[19] Wadhams, P., Tucker, W.B., Krabill, W.B., Swift, R.N., Comiso, J.C. and Davis, R.N. (1992) Relationship between Sea Ice Free Board and Draft in the Arctic Basin, and Implication for Ice Thickness Monitoring. Journal of Geophysical Research, 97, 20325-20334. http://dx.doi.org/10.1029/92JC02014

[20] Cavalieri, D.J., Markus, T., Ivanof, A., Miller, J.A., Brucker, L., Sturm, M., Maslanik, J., Heinrichs, J.F., Gasiewski, A.J., Leuschen, C., Krabill, W. and Sonntag, J. (2012) A Comparison of Snow Depth on Sea Ice Retrievals Using Airborne Altimeters and AMSR-E Simulator. Geoscience and Remote Sensing, 50, 3027-3039.

[21] Worby, A.P., Markus, T., Steer, A.D., Lytle, V.I. and Massom, R.A. (2008) Evaluation of AMSR-E Snow Depth Product over East Antarctic Sea Ice Using in Situ Measurements and Aerial Photography. Journal of Geophysical Research, 113, Article ID: C05S94. 
Scientific Research Publishing (SCIRP) is one of the largest Open Access journal publishers. It is currently publishing more than 200 open access, online, peer-reviewed journals covering a wide range of academic disciplines. SCIRP serves the worldwide academic communities and contributes to the progress and application of science with its publication.

Other selected journals from SCIRP are listed as below. Submit your manuscript to us via either submit@scirp.org or Online Submission Portal.
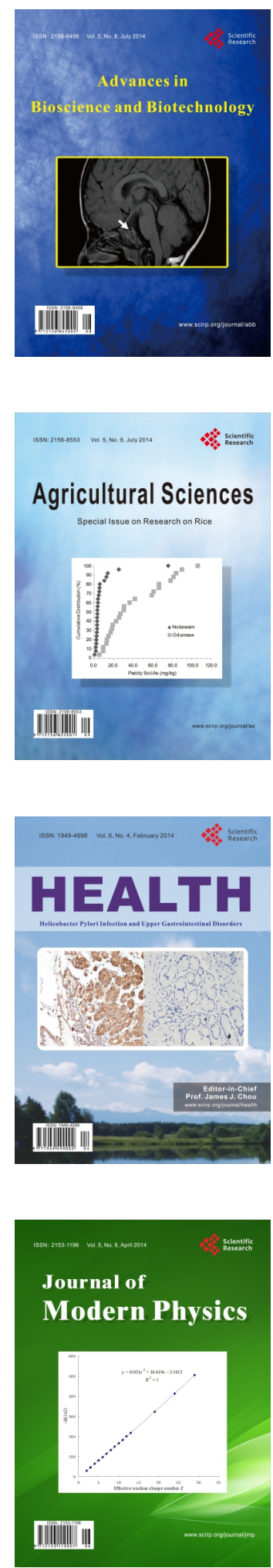
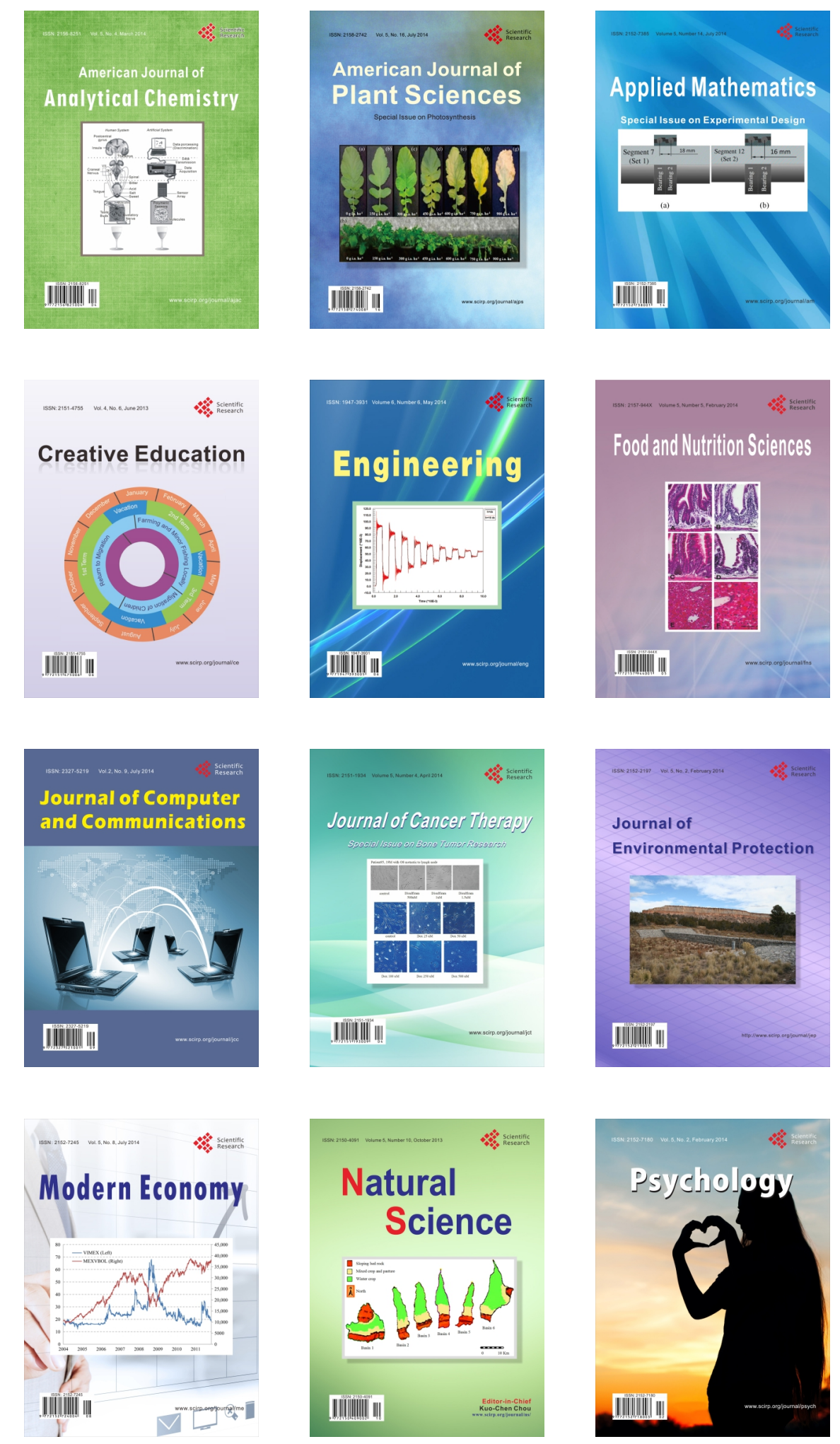